\title{
Visiting Professorship in Hospital Medicine: An Innovative Twist for a Growing Specialty
}

\author{
Ethan Cumbler, MD${ }^{1 \star}$, Carrie Herzke, MD², Roger Smalligan, MD³ , Jeffrey J. Glasheen, MD¹, \\ Cheryl O’Malley, MD', J. Rush Pierce Jr. MD5
}

\begin{abstract}
${ }^{1}$ Department of Medicine, University of Colorado School of Medicine, Aurora, Colorado; 2Department of Medicine, Johns Hopkins University School of Medicine, Baltimore, Maryland; ${ }^{3}$ Department of Medicine, Texas Tech University Health Sciences Center, Lubbock, Texas; ${ }^{4}$ Department of Medicine, University of Arizona College of Medicine-Phoenix, Phoenix, Arizona; ${ }^{5}$ Department of Medicine, University of New Mexico School of Medicine, Albuquerque, New Mexico.
\end{abstract}

INTRODUCTION: As an emerging and rapidly growing specialty, academic hospitalists face unique challenges in career advancement. Key mentoring needs, especially developing reputation and relationships outside of their institution are often challenging.

METHODS: We describe the structure of a novel Visiting Professorship in Hospital Medicine Program. It utilizes reciprocal exchanges of hospitalist faculty at the rank of late assistant to early associate professor. The program is designed explicitly to facilitate spread of innovation between institutions through a presentation by the visiting professor and exposure to an innovation at the host hospital medicine group. It provides a platform to advance the career success of both early- and midcareer hospitalist faculty through 1-on-1 coaching sessions between the visiting professor and early-career faculty at the host institution and commitment by visiting professors to engage in mentoring after the visit.
RESULTS: Five academic hospitalist groups participated. Seven visiting professors met with 29 early-career faculty. Experience following faculty exchange visits demonstrates program effectiveness, as perceived by both early-career faculty and the visiting professors, in advancing the goals of mentorship and career advancement. One-year follow-up suggests that $62 \%$ of early-career faculty will engage in subsequent interactions with the visiting professor, and half report spread of innovation between academic hospital medicine groups.

CONCLUSIONS: The Visiting Professorship in Hospital Medicine offers a low-cost framework to promote collaboration between academic hospital medicine groups and facilitate interinstitutional hospitalist mentoring. It is reported to be effective for the goal of professional development for midcareer hospitalists. Journal of Hospital Medicine 2016;11:714-718. (c) 2016 Society of Hospital Medicine
Hospital medicine is an emerging specialty comprised predominantly of early-career faculty, often less than 5 years postresidency and predominately at instructor or assistant professor level. ${ }^{1}$ Effective mentoring has been identified as a critical component of academic success. ${ }^{2,3}$ Published data suggest that most academic hospitalists do not have a mentor, and when they do, the majority of them spend less than 4 hours per year with their mentor. ${ }^{2}$ The reasons for this are multifactorial but largely result from the lack of structure, opportunities, and local senior academic hospitalists. ${ }^{1,4}$ Early-career faculty have difficulty establishing external mentoring relationships, and new models beyond the traditional intrainstitutional dyad are needed. ${ }^{3,4}$ The need for mentors and structured mentorship networks may be particularly high in hospital medicine. ${ }^{5}$

\footnotetext{
*Address for correspondence and reprint requests: Ethan Cumbler MD, Associate Professor of Medicine, University of Colorado School of Medicine, 12401 E. 17th Avenue, Mail Stop F782, Aurora, CO 80045; Telephone: 720-848-4289; Fax: 720-848-4293;

E-mail: ethan.cumbler@ucdenver.edu
}

Additional Supporting Information may be found in the online version of this article.

Received: December 18, 2015; Revised: April 12, 2016; Accepted: April 19, 2016

2016 Society of Hospital Medicine DOI 10.1002/jhm.2625

Published online in Wiley Online Library (Wileyonlinelibrary.com).
The Visiting Professorship in Hospital Medicine Program was designed to promote cross-institutional mentorship, share hospitalist innovations, and facilitate academic collaboration between hospitalist groups. We describe the design and early experience with this program across 5 academic hospital medicine programs.

\section{PROGRAM DESIGN}

\section{Objectives}

The program was designed to promote mentoring relationships between early-career hospitalist faculty and a visiting professor from another academic hospital medicine group. The program sought to provide immediate career advice during the visits, but also create opportunities for long-term mentorship and collaboration between institutions. Goals for each visiting professorship included: (1) follow-up contact between earlycareer faculty and visiting professor in the 6 months following the visit, (2) long-term mentoring relationship with at least 1 early-career faculty at the visited institution, and (3) identification of opportunities for interinstitutional collaboration to disseminate innovations.

\section{Selection of Sites and Faculty}

The first 2 academic medical centers (AMCs) for the visiting professorship exchange designed the program (University of Colorado and University of New Mexico). In 
subsequent years, each participating AMC was able to solicit additional sites for faculty exchange. This model can expand without requiring ongoing central direction. No criteria were set for selection of AMCs. Visiting professors in hospital medicine were explicitly targeted to be at midcareer stage of late assistant professor or early associate professor and within 1 to 2 years of promotion. It was felt that this group would gain the maximal career benefit from delivering an invited visit to an external AMC, yet have a sufficient track record to deliver effective mentoring advice to early-career hospitalists. The hospitalist group sending the visiting professor would propose a few candidates, with the innovations they would be able to present, and the hosting site would select 1 for the visit. Early-career faculty at the hosting institution were generally instructor to early assistant professors.

\section{Visit Itinerary}

The visit itinerary was set up as follows:

1. Visiting professor delivers a formal 1-hour presentation to hospitalist faculty, describing an innovation in clinical care, quality improvement, patient safety, or education.

2. Individual meetings with 3 to 5 early-career hospitalists to review faculty portfolios and provide career advice.

3. Group lunch between the visiting professor and faculty with similar interests to promote cross-institutional networking and spark potential collaborations.

4. Meeting with hospital medicine program leadership.

5. Visiting professor receives exposure to an innovation developed at the hosting institution.

6. Dinner with the hosting faculty including the senior hospitalist coordinating the visit.

In advance of the visit, both early-career faculty and visiting professors receive written materials describing the program, its objectives, and tips to prepare for the visit (see Supporting Information in the online version of this article). The curricula vitae of early-career faculty at the hosting institution were provided to the visiting professor. Visit costs were covered by the visiting professor's institution. Honoraria were not offered.

\section{Program Evaluation}

Within a month of each visit, a paper survey was administered to the visiting professor and the faculty with whom she/he met. In addition to demographic data including gender, self-reported minority status, academic rank, years at rank, and total years in academic medicine, the survey asked faculty to rate on a 5-point Likert scale their assessment of the usefulness of the visit to accomplish the 4 core goals of the program: (1) cross-institutional dissemination of innovations in clinical medicine, education, or research; (2) advancing the respondent's academic career; (3) fostering cross-institutional mentor-mentee relationships; and (4) promoting cross-institutional collaborations. Free-text responses for overall impression of program and suggestions for improvement were solicited.

At the time of this writing, 1 year has passed from the initial visits for the first 3 visiting professorships. A 1year follow-up survey was administered assessing (1) total number of contacts with the visiting professor in the year following the visit, (2) whether a letter of recommendation resulted from the visit, (3) whether the respondent had seen evidence of spread of innovative ideas as a result of the program, (4) participation in a cross-institutional collaboration as a result of the program, and (5) assessment of benefit in continuing the program in the next year. The respondents were also asked to rate the global utility of the program to their professional development on a 5-point scale ranging from "not at all useful" to "very useful" ("Thinking about what has happened to you since the visit a year ago, please rate the usefulness of the entire program to your professional life: overall usefulness for my professional development.”). Domain-specific utility in improving clinical, research, quality improvement, and administrative skills were also elicited (results not shown). Finally, suggestions to improve the program for the future were solicited. The Colorado Multiple Institutional Review Board determined that the study of this faculty development program did not qualify as human subjects research, and subjects were therefore not asked to provide informed consent for participation.

\section{RESULTS}

To date, 5 academic medical centers have participated in the visiting professorship program, with 7 visiting professors interacting with 29 early-career faculty. Of the 29 early-career faculty, $72 \%(21 / 29)$ were at the rank of assistant professor, 17\% (5/29) instructor, 7\% (2/29) residents with plans to hire, and 3\% (1/29) associate professor. The median was 2 years in academic medicine and 1 year at current academic rank. Forty-one percent (12/29) were women and $7 \%(2 / 29)$ identified as ethnic minority. Of the 7 visiting professors, $57 \%$ (4/7) were assistant professor and $43 \%(3 / 7)$ were associate professors. The median was 5 years in academic medicine, 29\% (2/7) were women, and none identified as ethnic minority.

Immediate postvisit survey response was obtained for all participating faculty. In the immediate postvisit survey, on a 5-point Likert scale, the 29 early-career faculty rated the visit: 4.4 for "promoting cross-institutional dissemination of innovations," 4.2 for "advancing my academic career," 4.2 for "fostering cross-institutional mentor-mentee relationships," and 4.4 for "promoting cross-institutional collaborations." Ninety-three percent (26/28 accounting for 1 nonresponse to this question) reported the visiting professorship had high potential to disseminate innovation (rated greater than 3 on the 5 -point Likert score). Eighty-three percent (24/29) of the early-career faculty rated the visit highly useful in advancing their career, $76 \%(22 / 29)$ responded that the visit was highly likely to foster external mentorship 
TABLE 1. Comments From Faculty About Visiting Professorship in Hospital Medicine Program

\begin{tabular}{l}
\hline Visiting Professors ( $\mathrm{n}$ = 7) \\
\hline "I was very impressed with the degree of organization, preparation, and structure from [host \\
institution]. The project is a great concept and may well lead to similar and even more developed \\
ones in the future. It is very helpful to "get the pulse" on another program and to hear of some of the \\
same struggles and successes of another hospitalist program. The potential for cross-site \\
mentor-mentee relationships and collaborations is a win-win for both programs." \\
"Overall, this exchange is a great program. It is fun, promotes idea exchange, and is immensely \\
helpful to the visiting professor for promotion. Every meeting I had with faculty at [host institution] \\
was interesting and worthwhile. The primary challenge is maintaining mentorship ties and \\
momentum after the visit. I personally e-malled every person I met and received many responses, \\
including several explicit requests for ongoing advising and collaboration." \\
"I liked multidisciplinary rounding. Research club. Meeting with faculty and trying to find common \\
areas of interest." \\
"Most of the faculty I met with see value in being involved in systems/quality improvement, but most \\
do not express interest in specific projects. Areas needing improvement were identified by everyone I \\
met with so developing projects around these areas should be doable. They might benefit from \\
access to mentoring in quality improvement." \\
"Very worthwhile. Was really helpful to meet with various faculty and leadership to see similarities and \\
differences between our institutions. Generated several ideas for collaborative activities already. Also \\
really helpful to have a somewhat structured way to share my work at an outside institution, as well \\
as to create opportunities for mentor-mentee relationships outside my home institution."
\end{tabular}

Early-Career Faculty $(n=29)$

"I really enjoyed my individual meeting with [visiting professor]. She was helpful in reviewing current projects from another perspective and very helpful in making suggestions for future projects. Also enjoyed her Grand Rounds and plan to follow-up on this issue for possible cross-institutional collaboration."

"I think this is a great program. It definitely gives us the opportunity to meet people outside of the [host institution] community and foster relationships, "mentorship," and possible collaborations with projects and programs."

"I think this is a fantastic program so far. VVisting professor] was very energetic and interested in making the most of the day. She contacted me after the visit and offered to keep in touch in the future. Right now I can see the program as being most useful in establishing new mentor/mentee relationships."

"It was fantastic to meet with [visiting professor] and get a sense for his work and also brainstorm about how we might do similar work here in the future (eg, in high-value care). It was also great to then see him 2 days later at [national conference]. I feel this is a great program to improve our connections cross-institutionally and hopefully to spark some future collaborations."

"Incredibly valuable to promote this kind of cross-pollination for both collaboration and innovation." "Wonderful, inspiring, professionally advantageous."

"Good idea. Good way to help midcareer faculty with advancement. Offers promise for collaboration of research/workshops."

\begin{tabular}{|c|c|}
\hline \multicolumn{2}{|c|}{ Suggestions for Improvement } \\
\hline "Please have e-mails of the folks we meet available immediately after the visit. It is hard to know if & "I feel like I may be a bit early on to benefit as much as I could have." \\
\hline anyone felt enough of a connection to want mentorship from me." & "Nice to have personal access to accomplished faculty from other institutions. Their perspective and \\
\hline $\begin{array}{l}\text { "Develop a mentorship program for quality improvement. As part of this exchange, consider treating } \\
\text { visits as similar to a consultation. Have visitor with specific focus that they can offer help with." }\end{array}$ & $\begin{array}{l}\text { career trajectory don't always align due to differences in institution culture, specifics of promotion } \\
\text { process, and so on, but still a useful experience." }\end{array}$ \\
\hline "Share any possible more-formal topics for discussion with leadership prior to the visit so can prepare & "For early career faculty, more discussions prior in regard to what to expect." \\
\hline ahead of time (eg, gather information they may have questions on). Otherwise it was great!" & "Great idea. Would have loved to be involved in more aspects. More time for discussion would have \\
\hline "A question is who should continue to push? Is it the prospective mentee, the mentee's institution, an & been good. Did not get to discuss collaboration in person." \\
\hline so on?" & "Great to get to talk to someone from totally different system. Wish we had more time to talk." \\
\hline
\end{tabular}

relationships, and 90\% (26/29) reported the visit highly effective in promoting cross-institutional collaborations. In the immediate postvisit survey, the 7 visiting professors rated the visit 4.9 for "promoting cross-institutional dissemination of innovations," 4.3 for "advancing my academic career," 4.0 for "fostering cross-institutional mentor-mentee relationships," and 4.3 for "promoting cross-institutional collaborations."

Free-text comments from both visiting professors and early-career faculty were generally favorable (Table 1). Some comments offered constructive input on appropriate matching of faculty, previsit preparation, or desire for more time in sessions (Table 1).

One-year follow-up was obtained for all but 1 earlycareer faculty member receiving the follow-up survey, and all 3 visiting professors. Of the 3 visiting professorships that occurred more than 1 year ago, 16 mentorship contacts occurred in total (phone, e-mail, or in person) between 13 early-career faculty and 3 visiting professors in the year after the initial visits (range, 0-4 contacts). Follow-up contact occurred for 3 of 4 earlycareer faculty from the first visiting professorship, 3 of 5 from the second visiting professorship, and 2 of 4 from the third visiting professorship. One early-career faculty member from each host academic medical center had 3 or more additional contacts with the visiting professor in the year following the initial visit. Overall, 8/13 $(62 \%)$ of early-career faculty had at least 1 follow-up mentoring discussion. On 1-year follow-up, overall utility for professional development was rated an average of 3.5 by early-career faculty (with a trend of higher ratings of efficacy with increasing number of follow-up contacts) and 4.7 by visiting professors. Half (8/16) of the involved faculty report having seen evidence of cross-institutional dissemination of innovation. Ninetyfour percent (15/16) of participants at 1-year follow-up felt there was benefit to their institution in continuing the program for the next year.

Objective evidence of cross-institutional scholarship, assessed by email query of both visiting professors and senior hospitalists coordinating the visits, includes 2 collaborative peer reviewed publications including mentors and mentees participating in the visiting professorship. ${ }^{6,7}$ Joint educational curriculum development on high-value care between sites is planned. The Visiting Professorship in Hospital Medicine Program has resulted in 1 external letter to support a visiting professor's promotion to date. 


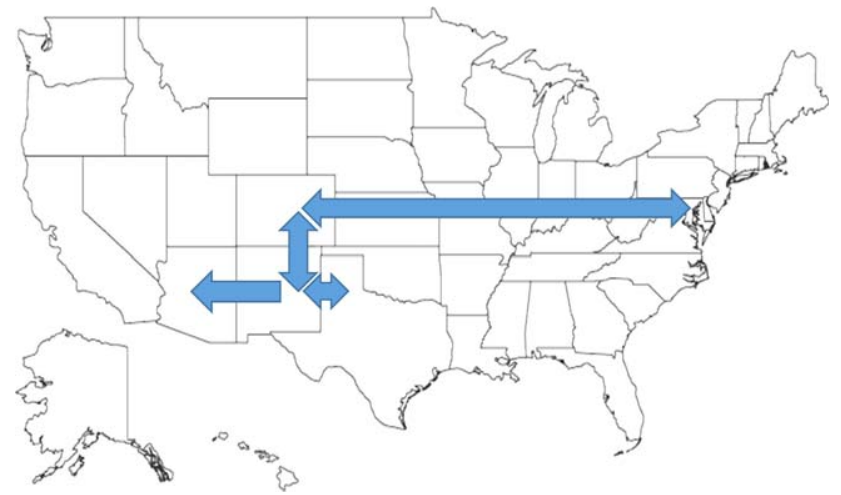

FIG. 1. Geographic representation of faculty exchanges to date.

\section{DISCUSSION}

Hospital Medicine is a young, rapidly growing field, hence the number of experienced academic hospitalist mentors with expertise in successfully navigating an academic career is limited. A national study of hospitalist leaders found that $75 \%$ of clinician-educators and $58 \%$ of research faculty feel that lack of mentorship is a major issue. ${ }^{1}$ Mentorship for hospitalist clinician-investigators is often delivered by nonhospitalists. $^{2,8}$ There is little evidence of external mentorship for academic clinician-educators in hospital medicine. ${ }^{1}$ Without explicit programmatic support, many faculty may find this to be a barrier to career advancement. A study of successfully promoted hospitalists identified "difficulty identifying external senior hospitalists to write letters in support of promotion" as an obstacle. ${ }^{9}$ Our study of the Visiting Professorship in Hospital Medicine Program found that earlycareer faculty rated the visit as useful in advancing their career and fostered external mentorship relationships. Subsequent experience suggests more than half of the early-career faculty will maintain contact with the visiting professor over the year following the visit. Visiting professors rate the experience particularly highly in their own career advancement.

The hospitalist movement is built on a foundation of innovation. The focus of each presentation was on an innovation developed by the visiting professor, and each visit showcased an innovation of the visited institution. This is distinct from traditional Hospital Grand Rounds, which more often focus on basic science research or clinical pathophysiology/disease management based on subspecialty topics. ${ }^{10}$ The Visiting Professorship in Hospital Medicine Program was judged by participants to be an effective means of spreading innovation.

Insights from experience with the Visiting Professorship in Hospital Medicine Program include the importance of preliminary work prior to each visit. Program directors need to attend closely to the fit between the interests and career path of the visiting professor and those of the early-career faculty. The innovations being shared should be aligned with organizational interests to maximize the chance of subsequent spread of the innovation and future collaboration. Providing faculty information about the objectives of the program in advance of the visit and arranging an exchange of curricula vitae between the early-career faculty and the visiting professor allows participants to prepare for the in-person coaching. Based on comments from participants, prompting contact from the visiting professor after the visit may be helpful to initiate the longitudinal relationship. We also found that early-career faculty may not be aware of how to effectively use a mentoring relationship with an external faculty member. Training sessions for both mentors and mentees on effective mentorship relationships before visiting professorships might improve earlycareer faculty confidence in initiating relationships and maximize value from mentor coaching.

A key issue is finding the right level of career maturity for the visiting professor. Our approach in selecting visiting professors was congruent with utilization of midcareer peer "coaches" employed by intrainstitutional hospital medicine mentoring programs. ${ }^{11}$ The visiting professor should have sufficient experience and accomplishments to be able to effectively counsel junior faculty. However, it is important that the visiting professor also has sufficient time and interest to take on additional mentees and to be a full participant in shared scholarship projects emerging from the experience.

This study represents the experience of 5 mature academic hospitalist groups, and results may not be generalizable to dissimilar institutions or if only the most senior faculty are selected to perform visits. There is an inherent selection bias in the choice of both visiting professor and early-career faculty. The small sample size of the faculty exposed to this program is a limitation to generalizability of the results of this evaluation. Whether this program will result in greater success in promotion of academic hospitalists cannot be assessed based on the follow-up available. The Visiting Professorship in Hospital Medicine Program has continued to be sustained with an additional academic medical center enrolled and 2 additional site visits planned. The costs of the program are low, largely air travel and a night of lodging, as well as nominal administrative logistical support. Perceived benefits by participants and academic medical centers make this modest investment worth considering for academic hospitalist groups.

\section{CONCLUSIONS}

The Visiting Professorship in Hospital Medicine Program offers structure, opportunities, and access to senior mentors to advance the development of earlycareer hospitalists while spreading innovation to 
distant sites. It is assessed by participants to facilitate external mentoring relationships and has the potential to advance the careers of both early-career faculty as well as the visiting professors.

Disclosure: Nothing to report.

\section{References}

1. Harrison R, Hunter AJ, Sharpe B, Auerbach AD. Survey of US academic hospitalist leaders about mentorship and academic activities in hospitalist groups. J Hosp Med. 2011;6:5-9.

2. Reid MB, Misky GJ, Harrison RA, Sharpe B, Auerbach A, Glasheen JJ. Mentorship, productivity, and promotion among academic hospitalists. J Gen Intern Med. 2012;27(1):23-27.

3. Pololi L, Knight D. Mentoring faculty in academic medicine: a new paradigm? J Gen Intern Med. 2005;20(9):866-870.

4. Flanders SA, Centor B, Weber V, McGinn T, DeSalvo K, Auerbach A. Challenges and opportunities in academic hospital medicine: report from the Academic Hospital Medicine Summit. J Hosp Med. 2009;4: 240-246.

5. Wiese J, Centor R. The need for mentors in the odyssey of the academic hospitalist. J Hosp Med. 2011;6:1-2.

6. Pell J, Rao D, Thurman L, Scott SJ. Procedural skills for hospitalists. Hosp Med Clin. 2016;5:114-136.

7. Ismaael TG, Zamora EM, Khasawneh FA. Cedecea davisae' s role in a polymicrobial lung infection in a cystic fibrosis patient. Case reports in infectious diseases. Case Rep Infect Dis. 2012;2012:176864.

8. Howell E, Kravet S, Kisuule F, Wright SM. Innovative approach to supporting hospitalist physicians towards academic success. J Hosp Med. 2008;3: 314-318.

9. Leykum LK, Parekh VI, Sharpe B, Boonyasai RT, Centor RM. Tried and true: a survey of successfully promoted academic hospitalists. J Hosp Med. 2011;6:411-415.

10. Van Hoof TJ, Monson RJ, Majdalany GT, Giannotti TE, Meehan TP. A case study of medical grand rounds: are we using effective methods? Acad Med. 2009;84(8):1144-1151.

11. Sehgal NL, Sharpe BA, Auerbach AA, Wachter RM. Investing in the future: building an academic hospitalist faculty development program. J Hosp Med. 2011;6:161-166. 